\title{
ChemComm
}

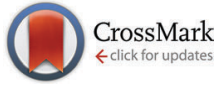

Cite this: Chem. Commun., 2015, 51, 1693

Received 3rd November 2014

Accepted 8th December 2014

DOI: $10.1039 / c 4 c c 08743 g$

www.rsc.org/chemcomm

\section{Mixed diboration of alkenes in a metal-free context $\uparrow$}

\author{
Nuria Miralles, Jessica Cid, Ana B. Cuenca, Jorge J. Carbó* and Elena Fernández*
}

Experimental and theoretical rationalization on regioselective mixed diboration of alkenes, with the unsymmetrical diboron reagent BpinBdan, providing the protecting Bdan moiety in the internal position.

Catalytic diboration reactions have been deeply studied from two standard perspectives: (1) the use of symmetrical diborons such as $\mathrm{B}_{2} \mathrm{pin}_{2}$ and $\mathrm{B}_{2} \mathrm{cat}_{2}$ ( pin = pinacolate and cat = catecholate $)$ and (2) the need of transition metal complexes to activate the diborons and transfer the two boryl units to unsaturated substrates promoting the 1,2-addition. ${ }^{1-3}$ Even nanoporous materials have been used to strategically activate the symmetrical diboron reagents to enhance the chemoselectivity of the reaction, avoiding secondary reactions involved in boryl addition. ${ }^{4}$ But two recent stalwart linchpins have changed the concept of diboration reactions.

First, the diboron reagent can be activated by simple alkoxides, ${ }^{5}$ to enhance the nucleophilic character of the trivalent boryl moiety and force the olefin to act as an electrophile (Scheme 1). ${ }^{6}$ This pull-push effect of diborons ${ }^{7}$ has gained potential application not only in enantioselective and diastereoselective diborations, ${ }^{8}$ but also in generating unusual stereoselectivity in the elegant trans 1,2-diboration assisted by a propargylic alcohol unit. ${ }^{9}$

The second interesting input is the use of unsymmetrical diborons to difunctionalise targeted compounds. However,

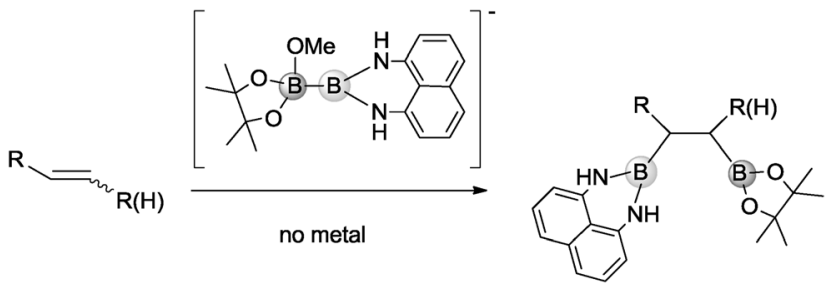

Scheme 1 Mixed organocatalytic diboration of alkenes with the $\mathrm{MeO}^{-} \rightarrow$ Bpin-Bdan adduct.

Department Quimica Física i Inorgànica, University Rovira $i$ Virgili,

C/Marcel-lí Domingo s/n, Tarragona, Spain.E-mail: mariaelena.fernandez@urv.cat, j.carbo@urv.cat

$\dagger$ Electronic supplementary information (ESI) available. See DOI: 10.1039/c4cc08743g despite the fact that several efforts have been devoted to perform mixed diboration reactions, only Bpin-Bdan (dan $=1,8$ diaminonaphthalene) has been successfully activated by Ir and Pt complexes and applied to the diboration of alkynes, giving the 1-alkene 1,2-diboronate derivative as the major regioisomer with the protecting Bdan unit at the terminal position. ${ }^{10}$ Interestingly, organoboranes with C-Bdan moieties are particularly easy to handle since the dan moiety acts as a masking group on $\mathrm{B} .{ }^{11}$ Alternative unsymmetrical diboron compounds of the type pinB$\mathrm{B}\left[(\mathrm{NR})_{2} \mathrm{C}_{6} \mathrm{H}_{4}\right]\left(\mathrm{R}=\mathrm{Me}, \mathrm{Bn}, \mathrm{SiMe}_{3}\right)$ have been recently isolated, but their application in catalysis has not yet been developed. ${ }^{12}$

Combining both challenges, we became interested in activating unsymmetrical diborons, such as Bpin-Bdan, with an alkoxide to generate the corresponding Lewis acid-base adduct and conduct an easy mixed diboration reaction, in the absence of metals or additives. Our goal was challenging, as the control of the diborated regioisomer in the organocatalytic approach could be a matter of concern. Nevertheless previous studies have shown that the $\mathrm{MeO}^{-} \rightarrow$ Bpin-Bdan adduct is formed preferentially because the $\pi$-donation from the lone pair of nitrogen to the empty orbital of boron protects the Bdan moiety from alkoxide attack. ${ }^{13}$ These conditions allowed the selective delivery of Bdan as a nucleophile. In this scenario, our objective in the present work is to activate the Bpin-Bdan reagent with methoxide and control the regioselective addition of Bdan and Bpin moieties to alkenes (Scheme 1).

We first attempted to find the optimal conditions for the diboration of allylbenzene (1) with Bpin-Bdan. When the reaction was carried out in THF as a solvent, at $70{ }^{\circ} \mathrm{C}$, and 2 eq. of $\mathrm{MeOH} / 30 \mathrm{~mol} \%$ of $\mathrm{Cs}_{2} \mathrm{CO}_{3}$, (in order to mimic the reaction conditions used with $\left.\mathrm{B}_{2} \mathrm{pin}_{2}\right),{ }^{5}$ we found that no diborated product was formed. Introducing $\mathrm{MeOH}$ as the solvent seemed to favour the reaction outcome, and moderate conversion from substrate 1 was achieved (Table 1, entry 1 ). The ${ }^{1} \mathrm{H}$ NMR spectra of the crude reaction show two different groups of signals for the diborated product in a ratio of $4 / 1$. The ${ }^{1} \mathrm{H}$, NOESY $1 \mathrm{D}$ experiment demonstrated that the major diborated regioisomer contained the Bdan moiety in the internal position. We next performed the 
Table $1 \mathrm{MeO}^{-}$assisted mixed diboration of terminal alkenes with Bpin-Bdan ${ }^{a}$

\begin{tabular}{|c|c|c|c|}
\hline$R_{\searrow}=r_{R^{\prime}(H)}$ & $\begin{array}{c}\underset{\text { pinB-Bdan }}{\longrightarrow} \\
70^{\circ} \mathrm{C}, \mathrm{MeOH}, \\
\mathrm{Cs}_{2} \mathrm{CO}_{3} \\
12 \mathrm{~h} \\
\end{array}$ & $\left.\sum_{\mathbf{B}}^{\mathrm{R}}\right\rangle_{\text {Bpin }}^{\mathrm{R}^{\prime}(\mathrm{H})}$ & $\underset{\text { Bpin }}{\mathrm{R}}\rangle_{\text {Bdan }}^{\mathrm{R}^{\prime}(\mathrm{H})}$ \\
\hline Entry Substrate & & $\begin{array}{ll}\mathrm{Cs}_{2} \mathrm{CO}_{3} & \text { Conv. }^{b} \\
(\mathrm{~mol} \%) & (\%)\end{array}$ & {$[\mathrm{IY}(\%)]^{c} \mathbf{a}$} \\
\hline
\end{tabular}

1<smiles>C=CCc1ccccc1</smiles>

$30 \quad 56 \quad 80 / 20 \quad 30$

$\begin{array}{llll}30 & 81 & 97 / 3 & 38\end{array}$

2

$\begin{array}{llll}50 & 88 & 94 / 6 & 40\end{array}$

3

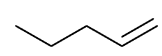

3

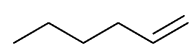

4

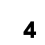

30

42

$88 / 12 \quad 17$
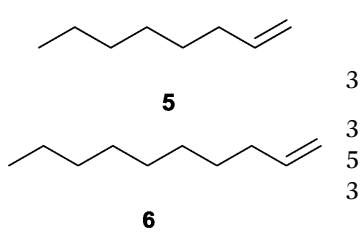

30
30
50
$30^{d}$

65

$92 / 18 \quad 25$

$91 / 9 \quad 70$

$80 / 20 \quad 62$

$90 / 10-$

${ }^{a}$ Reaction conditions: substrate $(0.5 \mathrm{mmol})$, Bpin-Bdan (1.1 eq.), $\mathrm{MeOH}(2 \mathrm{~mL}), 70{ }^{\circ} \mathrm{C}, 12 \mathrm{~h} .{ }^{b}$ Conversion and regioselectivity calculated by GC/MS from an average of two essays. ${ }^{c}$ Isolated yield of regioisomer a after purification by flash chromatography (see the ESI for details). d $30 \mathrm{~mol} \% \mathrm{NaOMe}$.

mixed diboration reaction with vinylcyclohexane and in the presence of $30 \mathrm{~mol} \%$ of $\mathrm{Cs}_{2} \mathrm{CO}_{3}$; conversion was high (81\%) but even more interestingly, the regioselectivity was almost quantitative for the diborated product with Bdan in the internal position (Table 1, entry 2). A similar trend was observed with $50 \mathrm{~mol} \%$ of $\mathrm{Cs}_{2} \mathrm{CO}_{3}$, with a slight increase in the global conversion (88\%). Subsequently, terminal olefins of variable alkyl chain lengths were subjected to the same organocatalytic diboration reaction with Bpin-Bdan, and despite the amount of base used, conversions were very high and regioselectivity was favoured towards the regioisomer with the Bdan moiety in the internal position, by an average ratio of 9/1 (Table 1, entries 3-6). Isolated yields of the major regioisomer were in general low since the mixed diborated product partially decomposed along the purification procedure (flash chromatography). However, product 6a could be successfully isolated in up to $70 \%$ IY, (Table 1, entry 6), as we noted that the longer the aliphatic chain, the higher is the stability of the diborated product. For comparison, when $\mathrm{NaOMe}$ was used as base (30 $\mathrm{mol} \%)$, the diboration of 6 was significantly diminished (Table 1, entry 6).

This new methodology to obtain mixed diborated products in the absence of transition metal complexes has a substrate scope limitation, because when vinylarenes were exposed to the diboration reaction with Bpin-Bdan under the same conditions, only the hydroborated product with Bdan in the terminal position was observed at the end of the reaction (Scheme 2).

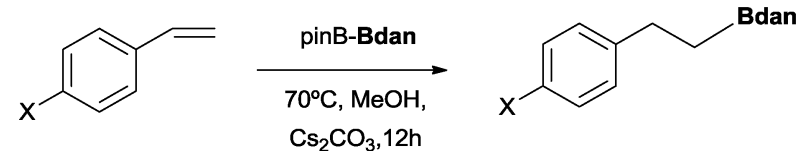

Scheme 2 Reactivity of vinylarenes with the $\mathrm{MeO}^{-} \rightarrow$ Bpin-Bdan adduct, $(\mathrm{X}=\mathrm{Me}, \mathrm{Cl}, \mathrm{H})$.

In the second set of experiments, internal olefins were subjected to the organocatalytic mixed diboration reaction and cis-3hexene (7) was moderately converted into the desired product $\mathbf{8}$, despite the amount of base used (Table 2, entry 1). The 1,2-addition of Bpin and Bdan moieties to cyclic olefins took place in a syn fashion, (Table 1, entries 2-4), and despite the moderate conversion of the internal olefins to the diborated product, compound $\mathbf{1 0}$ could be isolated in up to $42 \%$ IY (Table 2, entry 2).

In order to have more insight into the mechanism of the metalfree mixed diboration reaction, we conducted DFT calculations ${ }^{14}$ with the aim to understand the intrinsic control of the regioselectivity. Bo and co-workers have computationally characterised the mechanism of the organocatalytic diboration reaction of nonactivated olefins with the $\mathrm{B}_{2} \mathrm{pin}_{2}$ reagent. ${ }^{5}$ They proposed the nucleophilic attack of the boron reagent towards the substrate through an interaction between the strongly polarised B-B $\sigma$-bond of the activated diboron reagent and the antibonding $\pi^{*}$ orbital of the olefin. ${ }^{5}$ We used this proposal as a starting point to analyse the origin of the regioselectivity in diboration. Fig. 1 depicts the energy profile yielding the pathways of the two possible regioisomers.

Initially, the methoxide ions generated from $\mathrm{MeOH}$ in the presence of the base can form two different Lewis acid-base

Table $2 \mathrm{MeO}^{-}$assisted mixed diboration of internal alkenes with Bpin-Bdan ${ }^{a}$

Entry Substrate $\begin{aligned} & \mathrm{Cs}_{2} \mathrm{CO}_{3} \\ & (\mathrm{~mol} \%)\end{aligned} \begin{aligned} & \mathrm{Conv.}^{b} \\ & (\%)\end{aligned}$ Product $_{50}$

${ }^{a}$ Reaction conditions: substrate $(0.5 \mathrm{mmol})$, Bpin-Bdan (1.1 eq.), $\mathrm{MeOH}(2 \mathrm{~mL}), 70{ }^{\circ} \mathrm{C}, 12 \mathrm{~h} .{ }^{b}$ Conversion and calculated by GC/MS from an average of two essays. ${ }^{c}$ Isolated yield of regioisomer a after purification by flash chromatography (see the ESI for details). 


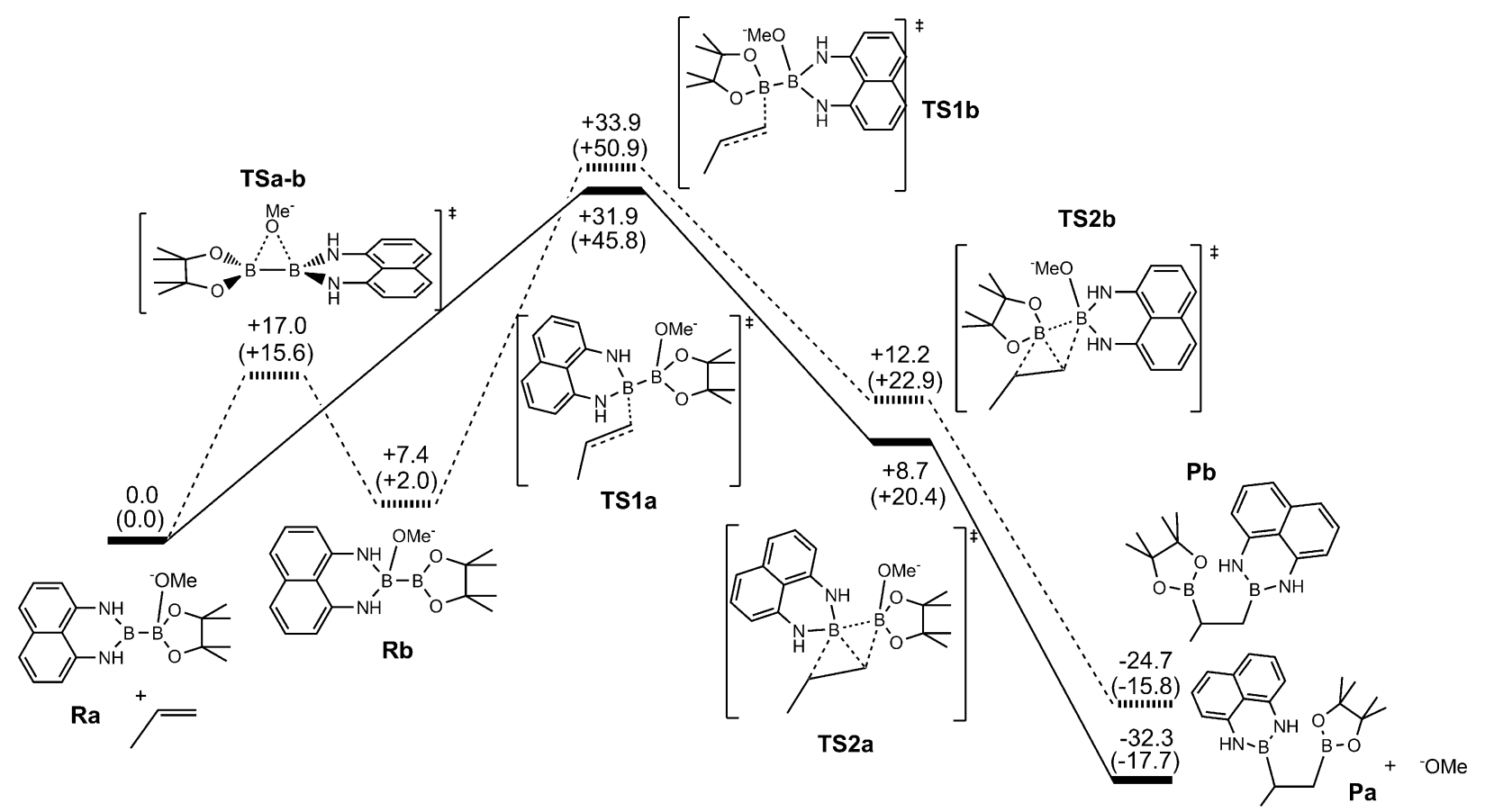

Fig. 1 Calculated energy profile for the organocatalytic diboration of propene with the Bpin-Bdan diboron reagent in the presence of $\mathrm{MeO}^{-}$. Solid lines correspond to the attack of the Bdan moiety and dashed lines correspond to the attack of the Bpin moiety. Electronic energies and Gibbs free energies in $\mathrm{MeOH}$ (in parentheses) in $\mathrm{kcal} \mathrm{mol}^{-1}$.

adducts with the unsymmetrical Bpin-Bdan: $\mathrm{MeO}^{-} \rightarrow$ BpinBdan (Ra) and $\mathrm{MeO}^{-} \rightarrow$ Bdan-Bpin (Rb). Recently, we have shown that the Bpin moiety is a stronger Lewis acid than Bdan, and consequently, the former adduct $\mathbf{R a}$ is $7.4 \mathrm{kcal} \mathrm{mol}^{-1}$ lower in energy than $\mathbf{R b} .{ }^{13}$ Here, Gibbs free energies including solvent effects via a continuum model show the same trends (Fig. 1). ${ }^{14}$ The energy barrier for the interconversion between the two adducts is modest (17.0 and $9.6 \mathrm{kcal} \mathrm{mol}^{-1}$ for $\mathbf{R a} \rightarrow \mathbf{R b}$ and $\mathbf{R b} \rightarrow \mathbf{R a}$, respectively), and more importantly, lower than the energy required to transfer the boron moieties to alkenes (see below).

Diboration occurs sequentially through two connected transition states (TS1 and TS2). ${ }^{5}$ In TS1, the nucleophilic $\mathrm{sp}^{2}$ boryl unit interacts with the terminal carbon of the alkene. ${ }^{15}$ Then, the quaternised boron atom becomes electrophilic and capable of interacting with the negatively charged olefin-boryl fragment, as described in TS2. Nucleophilic boryl attack on the terminal carbon to reach TS1 is the most energy demanding step and the one that determines the regioselectivity. As expected, ${ }^{13}$ the computed energy barrier for the attack of the Bdan group in Ra $\left(+31.9 \mathrm{kcal} \mathrm{mol}^{-1}\right)$ is higher than that for the Bpin group in $\mathbf{R b},\left(+26.5 \mathrm{kcal} \mathrm{mol}^{-1}\right)$. However, owing to the relatively low energy barrier for interconversion of $\mathbf{R a}$ and $\mathbf{R b}$ (see Fig. 1), the product distribution should be determined by the relative energy between the transition states of both paths, TS1a and TS1b. Thus overall, the attack on the alkene through the Bdan moiety (TS1a) is lower in energy than through Bpin (TS1b) by $2 \mathrm{kcal} \mathrm{mol}^{-1}$. The transition state TS1a is connected with another lower energy-lying transition state, TS2a, in which the Bdan moiety shifts to the internal olefinic carbon and the Bpin(OMe) moiety binds to the terminal carbon leading to the diborated product, Pa, and a methoxide molecule (see Fig. 1). These results are in good agreement with experimentally observed quantitative selectivity for Bdan addition in the internal position, albeit with non-negligible formation of the opposite regioisomer. Moreover, they explain the observed regioselectivity that is opposite to that found for diboration of alkynes by Ir and Pt complexes. ${ }^{10}$ In our case, the alkoxide Lewis base does not only activate the boron-boron bond, but also inverts its polarity driving diboron addition to a specific regioisomer.

Finally, we performed additional calculations to gain some insight into the substrate dependence of the reaction outcome: diboration $v s$. hydroboration. The mechanistic proposal by Bo and co-workers can also explain the hydroboration side reaction. ${ }^{5}$ According to this mechanism, when the system reaches transition state TS1, the reaction path bifurcates connecting with transition state TS2 or with intermediate I1 that yields hydroboration product via protonation and releases Bpin-OMe (see Scheme 3). For styrene, the computed energy of TS1a and I1a is lowered substantially compared to propene (Scheme 3). The phenyl substituent of the alkene stabilizes the negative charge generated at the internal alkene carbon, as well as the negative charge of intermediate I1a. Thus, the formation of hydroborated products is favoured for vinylarenes, which is in full agreement with the experimental findings.

In summary, we have found that mixed diboration reactions with the Bpin-Bdan reagent, can be carried out in a metal-free context, with high control of regioselectivity, locating the Bdan unit in the internal position. Ten new diborated products have been isolated, most of them in a pure form but some as a mixture of the two regioisomers. The B nucleophile in the Bdan 


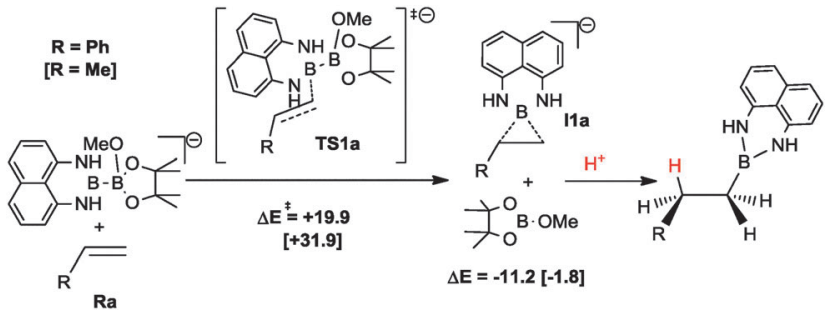

Scheme 3 Proposed mechanism for hydroboration of propene and styrene leading to Bdan transfer. Calculated electronic energies for styrene (and in brackets for propene) in kcal $\mathrm{mol}^{-1}$.

moiety is generated from the easily accessible, chemically resistant diboron reagent Bpin-Bdan and methoxide. The possibility to subsequently create an electrophilic Bpin unit on the activated diboron reagent makes the mixed diboration possible. Calculations on the energy profile for the organocatalytic diboration of propene with the Bpin-Bdan diboron reagent in the presence of alkoxide, support the experimental observation and rationalise the reaction outcome.

\section{Notes and references}

1 The original Pt mediated diboration of alkynes: T. Ishiyama, N. Matsuda, N. Miyaura and A. Suzuki, J. Am. Chem. Soc., 1993, 115, 11018; the original Rh mediated diboration of alkenes: T. R. Baker, P. Nguyen, T. B. Marder and S. A. Westcott, Angew. Chem., Int. Ed. Engl., 1995, 34, 1336; the original Pt mediated diboration of alkenes: T. Ishiyama, M. Yamamoto and N. Miyaura, Chem. Commun., 1997, 689.

2 Reviews: (a) J. Takaya and N. Iwasawa, ACS Catal., 2012, 2, 1993; (b) M. Suginome and T. Ohmura, In Boronic Acids, Wiley-VCH, New York, 2nd edn, 2011, vol. 1, 171; $(c)$ H. E. Burks and J. P. Morken, Chem. Commun., 2007, 4717; (d) J. Ramírez, V. Lillo, A. M. Segarra and E. Fernandez, C. R. Chim., 2007, 10, 138; (e) T. Ishiyama and N. Miyaura, Chem. Rec., 2004, 3, 271; $(f)$ T. B. Marder and N. C. Norman, Top. Catal., 1998, 63.

3 (a) T. Ishiyama, N. Matsuda, M. Murata, F. Ozawa, A. Suzuki and N. Miyaura, Organometallics, 1996, 15, 713; (b) T. Ishiyama, T. Kitano and N. Miyaura, Tetrahedron Lett., 1998, 39, 2357; (c) T. Ishiyama, S. Momota and N. Miyaura, Synlett, 1999, 1790; (d) F. Y. Yang and C.-H. Cheng, J. Am. Chem. Soc., 2001, 123, 761; (e) J. B. Morgan, S. P. Miller and J. P. Morken, J. Am. Chem. Soc., 2003, 125, 8702; $(f)$ N. F. Pelz, A. R. Woodward, H. E. Burks, H. E. Sieber and J. D. Morken, J. Am. Chem. Soc., 2004, 126, 16328; $(g)$ J. D. Sieber and J. P. Morken, J. Am. Chem. Soc., 2006, 128, 74; (h) H. Y. Cho and J. P. Morken, J. Am. Chem. Soc., 2008, 130, 16140; $(i)$ T. Ishiyama and N. Miyaura, J. Organomet. Chem., 2000, 611, 392; $(j)$ G. Lesley, P. Nguyen, N. J. Taylor, T. B. Marder, A. J. Scott, W. Clegg and N. C. Norman, Organometallics, 1996, 15, 5137; (k) R. L. Thomas, F. E. S. Souza and T. B. Marder, J. Chem. Soc., Dalton Trans., 2001, 1650; (l) S. Trudeau, J. B. Morgan, M. Shrestha and J. P. Morken,
J. Org. Chem., 2005, 70, 9538; (m) L. T. Kliman, S. N. Mlynarski and J. P. Morken, J. Am. Chem. Soc., 2009, 131, 13210; (n) J. R. Coombs, F. Haeffner, L. T. Kliman and J. P. Morken, J. Am. Chem. Soc., 2013, 135, 11222; (o) N. Iwadate and M. Suginome, J. Am. Chem. Soc., 2010, 132, 2548; ( $p$ ) V. Lillo, M. R. Fructos, J. Ramírez, A. A. C. Braga, F. Maseras, M. M. Díaz-Requejo, P. J. Pérez and E. Fernández, Chem. - Eur. J., 2007, 13, 2614-2621; (q) H. Yoshida, S. Kawashima, Y. Takemoto, K. Okada, J. Ohshita and K. Takaki, Angew. Chem., Int. Ed., 2012, 51, 235; (r) C. J. Adams, R. A. Baber, A. S. Batsanov, G. Bramham, J. P. H. Charmant, M. F. Haddow, J. A. K. Howard, W. H. Lam, Z. Lin, T. B. Marder, N. C. Norman and A. G. Orpen, Dalton Trans., 2006, 1370.

4 (a) J. Ramírez, M. Sanaú and E. Fernández, Angew. Chem., Int. Ed., 2008, 47, 5194; (b) Q. Chen, J. Zhao, Y. Ishikawa, N. Asao, Y. Yamamoto and T. Jin, Org. Lett., 2013, 15, 5766.

5 A. Bonet, C. Pubill-Ulldemolins, C. Bo, H. Gulyás and E. Fernández, Angew. Chem., Int. Ed., 2011, 50, 7158.

6 (a) J. Cid, H. Gulyás, J. J. Carbó and E. Fernández, Chem. Soc. Rev., 2012, 41, 3558; (b) J. Cid, J. J. Carbó and E. Fernández, Chem. - Eur. J., 2012, 18, 12794.

7 (a) K. Lee, A. R. Zhugralin and A. H. Hoveyda, J. Am. Chem. Soc., 2009, 131, 7253; (b) A. Bonet, H. Gulyás and E. Fernández, Angew. Chem., Int. Ed., 2010, 49, 5130; (c) C. Pubill-Ulldemolins, A. Bonet, C. Bo, H. Gulyás and E. Fernández, Chem. - Eur. J., 2012, 18, 1121; (d) C. Solé and E. Fernández, Angew. Chem., Int. Ed., 2013, 52, 11351; (e) H. Ito, Y. Horita and E. Yamamoto, Chem. Commun., 2012, 48, 8006; $(f)$ I. Ibrahem, P. Breistein and A. Córdova, Chem. - Eur. J., 2012, 18, 5175; $(g)$ H. Wu, S. Radomkit, J. M. O'Brien and A. H. Hoveyda, J. Am. Chem. Soc., 2012, 134, 8277; (h) C. Kleeberg, A. G. Crawford, A. S. Batsanov, P. Hodgkinson, D. C. Apperley, M. S. Cheung, Z. Y. Lin and T. B. Marder, J. Org. Chem., 2012, 77, 785; ( $i$ ) C. Sole, H. Gulyás and E. Fernández, Chem. Commun., 2012, 48, 3769.

8 (a) A. Bonet, C. Sole, H. Gulyás and E. Fernández, Org. Biomol. Chem., 2012, 10, 9677; (b) Th. P. Blaisdell, Th. C. Caya, L. Zhang, A. Sanz-Marco and J. P. Morken, J. Am. Chem. Soc., 2014, 136, 9256. 9 Y. Nagashima, K. Hirano, R. Takita and M. Uchiyama, J. Am. Chem. Soc., 2014, 136, 8532.

10 N. Iwadate and M. Suginome, J. Am. Chem. Soc., 2010, 132, 2548.

11 (a) H. Noguchi, K. Hojo and M. Suginome, J. Am. Chem. Soc., 2007, 129, 758; (b) N. Iwadate and M. Suginome, J. Organomet. Chem., 2009, 694, 1713; (c) H. Noguchi, T. Shioda, Ch.-M. Chou and M. Suginome, Org. Lett., 2008, 10, 377; (d) L. Iannazzo, K. P. C. Vollhardt, M. Malacria, C. Aubert and V. Gandon, Eur. J. Org. Chem., 2011, 3283; (e) X. Feng, H. Jeon and J. Yun, Angew. Chem., Int. Ed., 2013, 52, 3989; $(f)$ H. Yoshida, Y. Takemoto and K. Takaki, Chem. Commun., 2014, 50, 8299.

12 C. Borner and Ch. Kleeberg, Eur. J. Inorg. Chem., 2014, 2486.

13 J. Cid, J. J. Carbó and E. Fernández, Chem. - Eur. J., 2014, 20, 3616. 14 Calculations were performed using Gaussian09 (B3LYP functional) and the $6-31 \mathrm{~g}(\mathrm{~d}, \mathrm{p})$ basis set. In parenthesis we also provide the free energy corrections including the solvent effect of methanol $(\varepsilon=32.613)$ that introduced into the optimised vacuum geometries by using the IEFPCM continuum model. Main discussion used electronic energies because $\Delta G$ values overestimate the entropic cost for bimolecular processes. See the ESI $\dagger$ for details.

15 We have also considered the attack to the internal carbon of the alkene but the corresponding TSs are 2 and $5 \mathrm{kcal} \mathrm{mol}^{-1}$ higher than TS1a and TS1b. See the ESI $\dagger$ for details. 